DOI 10.20396/temáticas.v2i4.11672

\title{
Notas Sobre a Crise do Marxismo
}

\author{
Francisco Luiz Corsi
}

\section{InTRODUÇ̃̃o}

A crise do "socialismo real", culminada com o esfacelamento da U.R.S.S. e as profundas transformaçöes econômicas, sociais e políticas vividas pelo capitalismo, que apontam para a constituição de uma sociedade global, colocam inúmeras questóes para as Ciências Sociais. A magnitude dessas mudanças e seus respectivos problemas criam, ao mesmo tempo, um ambiente de certa perplexidade devido à velocidade dos acontecimentos e uma ebulição reflexiva e teórica, expressa, entre outras maneiras, pelo aparecimento de várias correntes pós-modernistas, pelo revigoramento da tradição liberal e pelas tentativas dos herdeiros do projeto da modernidade de refazer este projeto. Este clima de efervescência parece não atingir o marxismo. Essa teoria, aparentemente, rema contra a corrente, encontra-se em crise, classificada por alguns autores como terminal.

A forte ligação, entre a teoria e a prática constitutiva do marxismo, parece tornar o impacto dessas transformaçōes muito mais profundo nessa teoria do que em outras. De fato, o marxismo não pode ser analisado separadamente das vicissitudes do movimento socialista mundial, ao qual, há muito, encontra-se intimamente entrelaçado. A sorte dos dois parece se confundir.

Temáticas, Campinas, 3(4):1-20, jul./de\%. 1994 
$\Lambda$ crise do marxismo, não obstante ter na débâcle do chamado socialismo real seu epicentro, de forma alguma limita-se a esse ponto, que, pela extensão e profundidade dos acontecimentos a ele relacionado, tende a ofuscar outros fatores também de suma importancia. Com a introdução, no capitalismo, do padrão de acumulação flexível em substituição ao padrão fordista, tornou-se evidente a fragilização da classe operária, já delineada desde o pós-guerra. A informatização e a automação tendem, cada vez mais, a tornar a força de trabalho supérflua e criam formas de inserção no processo de trabalho que acabam fragmentando a classe trabalhadora. Esta, idealizada como o sujeito da revolução, mostra-se fragmentada, desorganizada e com uma consciência difusa; ao contrário de todas as expectativas de Marx. O sistema capitalista, apesar de estar em crise, demonstra uma vitalidade e um dinamismo que parecem jogar por terra as esperanças daqueles que acreditavam num fim próximo do sistema. A derrocada do socialismo real e a acelerada globalização do capitalismo parecem sugerir a inexistência de uma alternativa viável a esse modo de produçāo. Teríamos, assim, como diz Fukuyama, chegado ao fim da história. A sobreposição desses processos coloca em questão proposiçōes centrais do marxismo.

O objetivo deste artigo não é fazer uma ampla discussão acerca dos problemas teóricos da crise do marxismo, mas, sim, discutir a relação entre os acontecimentos mencionados e a crise do marxismo. Pretende-se apenas levantar alguns pontos para a reflexão de assunto tão vasto e complexo como esse.

\section{1- A Crise do Marxismo}

A crise do marxismo não é nenhuma novidade; pelo menos desde meados dos anos 70 é um tema recorrente na literatura. Castoriadis, em $A$ instituição imaginária da socicdade, texto de 1975, argumenta que o marxismo tornou-se ideologia nos termos definidos pelo próprio Marx:

Temáticas, Campinas, 3(4):1-20, jul./dez. 1994 
"um conjunto de idéass que se refere a uma realidade, nào para esclarecế-la e transformá-la, mas para cucobri-la c juslificá-la no imaginário, que permile às pessoas dizerem uma coisa e fazercm oulra, aprescntarem que não são".'

Concretamente, teria se tornado ideologia ao cumprir o papel de idéias e visões, justificadoras dos regimes socialistas existentes, não constituídos como Estados genuinamente proletários, ao servir de doutrina a "grupúsculos" auto-intitulados representantes da classe operária, mas que não passam de seitas de caráter religioso e, finalmente, ao estagnar-se como uma teoria crítica viva. Como ideologia, o marxismo deveria ser criticado e superado ençuanto tal.

O contexto dessas críticas era de fragmentação do marxismo em inúmeras variantes, não existindo mais um marxismo, mas vários. Fssa fragmentação ocorreu como conseqüencia da crise do stalinismo que, durante décadas, tiuha se constituido como o marxismo "oficial" a também dos embates, das vitórias e dos fracassos do movimento revolucionário em nivel mundial, nos anos 60 e $70 . \quad \Lambda$ invasão da llungria pelas tropas soviéticas, em 1956, parece ter sido o marco inicial desse processo. Depois desse acontecimento não mais era possível fechar os ollos à barbárie do stalinismo, o que levou inúmeros teóricos a reformular ou reinterpretar o marxismo, buscando o que consideravam ser o verdadeiro pensamento de Marx. Ou seja, pregavam uma volta a Marx. A tentativa de interpretação estruturalista do pensamento de Marx por Althusser é um exemplo desse movimento. ${ }^{2}$

'(ASSTORIADIS, Cornelius (1982). A instituţ̧ão imaginária da sociedade. $2^{\mathrm{a}}$ ed., Rio de Janeiro, Paz e Terra. Ver também ('OLLLEITI, Lucio (1983). Ullirapassando o marxismo e as adeologias. Rio de Janciro, Forense-Universitária.

"IIOBSBAWM, Eric J. "Marxismo Hoje: um balanço aberto". In: IIOBSBSAWM, Eric J. (org.) (1983). História do Marrismo. v. 11, P'rimeira P'arte, Rio de Janciro, P'at e Terra, p. 21.

Temáticas, Campinas, 3(4):1-20, jul./de\%. 1999 
Para ('astoriadis, essa volta ao pensamento "puro" de Marx seria bastante problemática, pois, para sermos coerentes com essa teoria, não poderíamos analisá-la independentemente da sua prática histórica e social. $\Lambda$ ssim, os diversos marxismos formariam as diferentes correntes de um programa prático e teórico embasado em Marx. ${ }^{3}$ Hobsbawm está próximo desse ponto de vista:

"Na medida que um conjunto de idéias sobrevive a quem o claborou, deixa de estar confinado ao ámbito do conteúdo $e$ das intenções originais. Nos limiles muito amplos, traçados pela capacidade exegética dos homens, ou até pela disponibilidade humana de declarar um nexo com predecessor amado ou predilcto, aquele bloco de idéias eslá sujeito a uma série imprevisivelmente vasta de mudanças e transformações práticas c teóricas (...) é amplo o espectro de idéias e de práticas que pretendem derivar dos textos de Marx". ${ }^{4}$

No entanto, Hobsbawm diverge da proposição de Castoriadis, segundo a qual deveríamos buscar na teoria marxista uma das causas importantes para a degenerescência dạ Revolução de Outubro de $1917 \mathrm{em}$ um regime extremamente autoritário e burocratizado. Ilobsbawm, apesar de considerar que qualquer teoria se modifici ao tornar-se força política importante, argumenta que a razão da degenerescencia do regime soviético encontra-se muito mais nas condiçoes históricas do momento que na teoria. O fato de as revoluçooes socialistas, no século $X X$, terem ocorrido em países não industrializados explicaria, em grande medida, a sua configuração posterior. ${ }^{5}$

Isto não quer dizer que uma análise crítica do marxismo deveria ater-se apenas à teoria. Pelo contrário, o próprio fato de o marxismo não só se propor como uma teoria, cujo objetivo é transformar a realidade, mas, sobretudo, devido à sua intensa ligação e influência

"(:ASTORIAI)IS, Cornelius. op. cil., p. 20.

'IIOBSBßBWM, Eric J. op. rit., p. 14.

"lalem, ibidem, P. 15.

Trmáticas, (ampinas, 3(4):1-20, jul./de\%, 1994 
no movimento operário, exige que qualquer anailise a seu respeito remeta is sua prática social, ao destino do movimento dos trabalhadores e ao contexto histórico. As vicissitudes da luta de classes e as transformaçōes no real questionam e colocam novos problemas ao marxismo de maneira muito mais intensa do que a outras teorias.

Para Lipiet\%, a desgraça do marxismo foi justamente o sen forte envolvimento com a prática social. Os fracassos e os dilemas estratégicos do movimento operário acabaram por dilacerá-lo, descaracterizando-o como programa de pesquisa e de ação. Perry Anderson considera justamente o contrário. $\Lambda$ distância da prática política, uma das características centrais do que ele denomina de marrismo ocidental, teria levado à estagnação da teoria, crescentemente academica e preocuparla com questöes filosóficas, deixando de lado questões mais ligadas à economia e à política. ${ }^{63}$

Para Anderson, o marxismo ocidental, fruto da derrota das revoluçoes na buropa ocidental, no início do século (e, por isso, deslocado da prática), esgoton-se entre o linal da década de 1960 e meados da seguinte, quando o ascenso do movimento operário, a revolução cultural chinesa, o ascenso dos movimentos revolucionários no Terceiro Mundo, as revoltas estudantis de 1968, a "Primavera de Praga" e, um pouco mais tarde, a crise econômica do capitalismo faziam crer que o marxismo retornaria às suas origens, entrelaçando novamente prática e teoria. Lsses acontecimentos geraram um amplo debate no marxismo, com desdobramentos práticos e teóricos.

lisse periodo, segundo o referido autor, foi de grande expansão do marxismo, em particular nos países anglo-saxóes até então praticamente imunes ao desenvolvimento das idéias de Marx. Não obstante persistirem linhas de continuidade com o marxismo ocidental,

${ }^{6}$ LIPIEYL", Alian (1991). " $\Lambda$ s crises do marxismo. Da teoria social ao principio de esperança". In: Novos Estudos CEBR.AP. São Paulo, n' 30 e ANIDERSON, Perry (1987). A crise da crise do marrismo. Introdução a um debate contemporáneo. $3^{\mathrm{a}}$ ed. Sĩo Paulo, Brasiliense. Os próximos parágrafos discutem esta ciltima obra.

Temáticas, Campinats, 3(4):1-20, jul./ de\% 1994 
o marxismo desse periodo voltou-se prioritariamente para questóes mais concretas. Os estudos acerca da economia, da política, do Fistado, das classes sociais e do socialismo passaram, em contraste com os temas filosóficos e culturais das décadas anteriores, a ocupar o centro das preocupaçoes marxistas. ${ }^{7}$

Contudo, quase simultaneamente a essa florescencia do marxismo, observa-se, já na segunda metade dos anos 70, uma crise aguda do marxismo francês, espanhol e italiano, mostrando o fôlego curto daquela fase de expansão. Em pouco tempo, o marxismo perdeu terreno nesses países:
“... em meio a uma recrudescéncia de violentas febres an- licomunistas na França e na llália, houve uma abrupta e ampla renúncia ao marxismo em bloco, por pensadores de geraçócs mais anligas $e$ mais recenles da esquerda. A recon- versão mais espelacular, a esse respeilo, foi talvez a de lucio Collelli, outrora o primeiro filósofo marxista na Itália, que no cspaço de trés ou qualro anos tornou-se inimigo agudo do marxismo e leal defensor de um liberalismo mais ou menos convencional (...). Na França, Sartre nos seus últimos anos seguiu sua trajelória própria da denúncia do comunismo à renúncia formal do marrismo, no scu caso em nome de um nco-anarquismo radical. a mudança, ou o declínio, dessas eminências nào foi, contudo, um caso isolado. Corrcspon- deu a uma mudança muilo mais ampla de disposiçóes nos círculos filosóficos e literários antes associados à esquerda".

O problema teórico chave, centro das discussōes nesse período dr recuo do marxismo, parece ser o papel dos sujeitos humanos na história e na sociedade, tema fundamental para o materialismo histórico. () avanço do marxismo estruturalista, capitancado por Althusser, ao reduzir os individuos a meros reflexos das estruturas sociais e considerar a história como um movimento diferenciado des-

\footnotetext{
${ }^{7} A N D E R S O N$, Perry. op. cil., pp. 25-26.

rIdem, ibidem, pp. 33-34.

Tematucas, (ampinas, 3(4):1-20, jul./de\%. 1994
} 
tas estruturas, levou o materialismo histórico à estagnação, sendo uma das causas de sua crise. Os movimentos sociais de 1968 evidenciaram a fragilidade dessas correntes. Mas, o materialismo histórico não estava morto. Obras como as de E. P. Thompson, ao recuperar o papel do sujeito humano e da cultura na explicação da relação entre estrutura e sujeito na sociedade e na história, mostram ainda a grande vitalidade do marxismo.

$\Lambda$ pesar dos intrincados problemas levantados pelo marxismo estruturalista de Althusser, que construíra uma teoria em que os sujeitos eram as estruturas sociais e não as classes e os indivídıos; pela tentativa feita por Mao 'Tsé-Tung e outros de reformular o marxismo, "colocando o movimento social - em lugar da evolução técnica - no coração" das transformaçōes históricas; e pelas avaliações críticas do socialismo real, a crise não era apenas teórica, mas sobretudo refletia os impasses da esquerda.

Para Anderson, a raiz da crise residia na incapacidade do marxismo em elaborar uma estratégia consistente capaz de derrubar o capitalismo e instaurar um socialismo verdadeiramente democrático. Isto porque o marxismo não tinha conseguido superar a fratura entre a teoria e a prática, embora houvessem ocorrido avanços nesse sentido, a partir de 1968. O esgotamento da Revolução Chinesa e, principalmente, o fracasso da estratégia eurocomunista, que levou o amplo movimento reformista a um beco sem saída, seriam as causas reais da crise. O fato de o eurocomunismo ser mais forte na Itália, França e Espanha explicaria, em grande medida, porque o marxismo entrou em colapso nessas regiões, em contraste com a expansão do materialismo histórico no mundo anglo-saxão.

Embora Anderson não descartasse a possibilidade de a crise estender-se ao mundo anglo-saxão, sua avaliação quanto às perspectivas do marxismo nessa região parecia otimista. Como podemos ver hoje, mais de dez anos após a publicação de seu texto, seu otimismo mostrou-se infundado. A crise também atingiu em cheio o marxismo 
inglês e norte-americano. Parece que ele não percebeu, ou ainda não tinha condições de fazê-lo àquela altura, que a crise do marxismo não se devia apenas à sua incapacidade de restabelecer uma ligação mais orgânica entre teoria e prática e uma estratégia alternativa para o socialismo, mas também vinculava-se a transformações mais profundas em curso, já há algum tempo, tanto no capitalismo como no socialismo real e que colocariam questões formidáveis para checar os próprios fundamentos da teoria.

$\mathrm{Na}$ década de 80 e nos primeiros anos da década atual, a crise do marxismo ganhou contornos dramáticos. A rigor parece que todo o edifício da teoria está em questão: a crise sacode

“... alé mesmo a arquitetura, o próprio 'núcleo duro' do que se chama marxismo, enquanto programa ao mesmo tempo de ação $c$ de pesquisa, enquanto concepção do mundo e da história. Não são mais apenas as análises $e$ as respostas que são postas $\mathrm{em}$ questão, mas as próprias questões, ou antes o interesse em as colocar (...). Näo se trata mais com certeza de crise no marxismo, pois esle não pode sair dela a não ser inscrevendo-se em uma problemática mais ampla, que pode não obstante guardar uma coloração marxista". ${ }^{9}$

$\Lambda$ questão que nos interessa enfrentar a partir da linha argumentativa seguida até aqui, consiste em saber em que medida esta crise, que sacode até o "núcleo duro" do marxismo, pode ser explicada pelas recentes transformações no capitalismo e no socialismo real.

\section{2- A Cuise do Sociahismo}

A crise dos regimes socialistas do leste europeu não foi uma crise qualquer: representa o fim de uma experiência, aberta em 1917, que se mostrou inviável historicamente. O socialismo soviético

${ }^{9}$ LIPIF,I'\%, Alian. op. cat., p. 101. 
demonstrou-se impermeável às tentativas de reformas de cima para baixo, iniciadas a partir de Gorbatchev e foi derrubado por uma verdadeira revolução popular. Habermas assinala que, não obstante as múltiplas formas dessa revoluçāo, ela pode ser considerada como una revolução recuperadora, por procurar a "recuperação de um desenvolvimento perdido". Um retorno à economia capitalista e às formas democráticas de governo, como se a experiência socialista fosse nada mais que um hiato histórico. ${ }^{10}$

$\Lambda$ crise do "socialismo real" começou a ficar evidente a partir dos anos 60, quando o regime soviético mostrou-se, de maneira cada vez mais clara, incapaz de acompanhar o desenvolvimento capitalista. Até a década de 1950, isso de forma alguma era evidente. O socialismo soviético, em contraste com o capitalismo, que vinha enfrentando recorrentes e profundas crises desde 1914, às quais punham em questão sua capacidade de sobreviver, apresentava a seu favor feitos aparentemente impressionantes. Basta lembrar que, enquanto os países capitalistas, nos anos 30, enfrentavam sua maior crise, a U.R.S.S. apresentava um crescimento significativo. Mas, com a recuperação do capitalismo a partir da Segunda Guerra Mundial, a situação mudou paulatinamente. A esclerose das sociedades tipo soviéticas salta aos olhos, quando o sistema capitalista entra em uma nova fase, com base em uma onda de inovaçōes tecnológicas e em uma globalização crescente da economia, das comunicações e da cultura.

O sistema soviético mostrou-se incapaz de desenvolver plenamente uma economia calcada em moderna tecnologia e capaz de satisfazer as necessidades de bens de consumo de sua população. De fato, esse sistema fracassou no referente à solução dos problemas

\footnotetext{
${ }^{10}$ II A BERMAS, Jurgen. "O que é socialismo hoje", p. 47. In: BLACKBURN, Robin (org.) (1992). Depois da queda. O fracasso do comunismo e o futuro do socialismo. Rio de Janeiro, Paz e Terra. A análise da crise do socialismo, a seguir, baseia-se neste livro, em particular nos artigos de Eric J. Hobsbawm: "Adeus a tudo aquilo" e "Renascendo das cinzas".
}

Temáticas, Campinas, 3(4):1-20, jul./dez. 1994 
econômicos. O relativo atraso tecnológico, a falta de racionalidade econômica, a baixa produtividade do trabalho e a ineficiência e o desperdício generalizados acarretaram um crescimento mais lento da economia soviética, minando a capacidade de a U.R.S.S. manter-se como uma super-potência. A tentativa, nessas condições, de continuar competindo com o capitalismo acelerou a crise do sistema. 'Também revelou-se impossível a tentativa de isolar as populações socialistas das informações a respeito do mundo ocidental em um contexto de crescente globalização da sociedade. Tais informaçōes evidenciavam a deterioração das condiçōes materiais e a falta de liberdade no mundo socialista. ${ }^{11}$

$\Lambda$ crise dos regimes socialistas foi engendrada, como mostrou Blackburn, por uma complexa articulação de problemas e contradiçōes internos e externos. Segundo Frederic Jamenson, a expansão e abertura internacional do capitalismo sem precedentes nos últimos 20 anos, levou a uma reestruturação de todo o sistema, o que nāo deixou de afetar drasticamente a U.R.S.S. e seus Estados clientes, quando estes tentaram estabelecer uma relação mais estreita com o mundo capitalista. ${ }^{12}$ Basicamente três questōes parecem consistir o cerne da crise do socialismo real. Questões que também representam desafios ao marxismo, se este pretende manter-se como uma teoria viva.

Em primeiro lugar, a falta de condições sociais, econômicas e políticas propícias ao desenvolvimento do socialismo na Rússia em 1917 (atraso econômico, falta de uma tradição democrática, classe trabalhadora de pequenas proporçōes etc.) e a constante pressão dos países capitalistas acabaram por descaracterizar o sistema. O modelo de socialismo construído nessas circunstâncias, apesar de ter sido relativamente eficiente no período de industrialização acelerada, apresenta-se hoje incapaz de responder aos desafios de uma econo-

\footnotetext{
"BLACKBURN, Robin. op. cit.

${ }^{12}$ Id., ibid. Ver artigo de Frederic Jameson "Conversas sobre a nova ordem mundial", pp. 216-234.

Temáticas, Campinas, 3(4):1-20, jul./dez. 1994
} 
mia transnacional. O fracasso da economia soviética não foi total; até a década de 1970 conseguia responder às necessidades básicas de moradia, saúde, alimentação e educação. Contudo, o socialismo soviético não passou de uma estratégia e de uma ideologia que visavam industrializar, de forma acelerada, países pobres. $\Lambda$ ausência dessas condiçōes, como assinalam vários autores, gerou uma vanguarda autoritária, que rapidamente transformou-se em uma espécie de oligarquia burocrática que prescreveu a democracia. ${ }^{13}$ Essa experiência foi fundamental para colocar em cheque a concepção da vanguarda e partido único como condutores do proletariado e da revolução que dominou por tanto tempo o marxismo.

Em segundo lugar, embora essa explicação tenha certo fundamento, parece difícil creditar unicamente ao atraso no desenvolvimento do capitalismo, a constituição de um regime burocrati\%ado e opressivo na U.R.S.S. Fortes indícios sugerem que a burocratiæação vincula-se à própria forma de organização da economia. $\Lambda$ tentativa de impor um plancjamento centralizado em uma economia complexa e de larga escala, ao requerer uma série de organismos técnicos de elaboração de projetos, de controle e de coordenação da vida economica nos seus mínimos detalhes, gerou inevitavelmente uma ampla burocracia. Esta, por ocupar posiçoes-chave no processo de decisões e no fluxo de informaçōes, contribuiu para a burocratização do sistema.

O planejamento central revelou-se inexequíivel e acabou por levar a economia soviética à estagnação e à crise. $A$ eliminação do mercado e sua substituição por um planejamento centralizado e burocratizado eliminou a concorrência na economia e, com ela, os estímulos para a introdução de novas tecnologias, além de inviabilizar qualquer forma de aproveitamento mais racional dos recursos. Assim, gerou-se um sistema econômico ineficiente. Devido à complexidade das relações intersetoriais, o número elevado de produtos, a burocra-

\footnotetext{
${ }^{13}$ BL.ACKIBURN, Robin. op. cit.
}

Temáticas, Campinas, 3(4):1-20, jul./de\%. 1994 
tização dos organismos responsáveis pelo planejamento e a impossibilidade de os consumidores expressarem de forma clara suas necessidades e desejos, tornou-se dificílima a compatibiliæação do volume e da qualidade da produção com o consumo, tanto entre os diferentes setores da economia quanto entre produção e consumo final. $\Lambda$ dificuldade básica parece ser a compatibilização e a coordenação entre as decisões microecônomicas e as decisões macroeconômicas na ausência de um parâmetro claro de cálculo econômico. $\mathrm{O}$ resultado foi uma cconomia com sérios problemas na alocação do trabalho social e, portanto, com baixíssimo nível de produtividade e elevados índices de desperdícios. A magnitude desses problemas chegou a ponto de inviabilizar, nos anos recentes, a reprodução ampliada da economia.

Dessa forma, o planejamento centralizado, pensado pela teoria marxista como um mecanismo capaz: de regular diretamente a distribuição social do trabalho e dos recursos; "de equilibrar a oferta e a demanda em termos físicos"; de distribuir o produto social de acordo com critérios sociais e de planejar os investimentos do conjunto da economia; e, assim, superar a irracionalidade inerente ao capitalismo, acabou gerando um sistema tão ou mais irracional yur o capitalismo, colocando em dúvida a viabilidade prática da proposta. O problema parece não se dever apenas à ausência de um planejamento democrático, mas parece ser intrínseco à própria proposta de planejar de maneira centralizada economias extremamente complexas. ${ }^{14}$

Hoje, ganha terreno dentro do pensamento de tradição marxista a idéia segundo a qual uma sociedade complexa não pode funcionar

\footnotetext{
${ }^{14}$ Idem, ibidem. Ver artigo do próprio Blackburn "O socialismo após o colapso", pP. 107-215 e BRUS., W. "O funcionamento de uma economia socialista”. In: HOBSBAWM, E. J. (org.) (1989), Mislória do Marxismo. O Marxismo hoje. Primeira Parte, vol., 11. Rio de Janciro, Paz c 'Terra.
}

T'emáticas, Campinas, 3(1):1-20, jul./de\%. 1994 
sem mercados. O desafio para o marxismo nesse aspecto parece consistir em elaborar uma proposta de socialismo compatível com a existência de mercados. ${ }^{15}$

Em terceiro lugar, o banimento da democracia das sociedades tipo soviéticas parece ter sido o fator central de seu desmoronamento. Bobbio ${ }^{16}$ assinala que o comunismo tornou-se uma caricatura de seus objetivos. A utopia de uma sociedade mais justa, igual e livre transformou-se no seu contrário, uma sociedade extremamente autoritária e desigual. Não por acaso o móvel dos estudantes da Praça da Paz Celestial, do Solidariedade e dos povos que puseram abaixo o "muro de Berlim" e as ditaduras do leste-europeu foi a luta pelos direitos humanos e pela democracia. A luta pelas liberdades individuais, de imprensa, de reuniāo, de opinião e de associação galvanizou esses povos para uma luta que podemos denominar de revolucionária.

A vitória dos bolcheviques, em 1917, implicou o predomínio, por décadas, de sua concepção autoritária de socialismo no seio do marxismo, calando concepções democráticas como as de Rosa Luxemburgo. Os bolcheviques e, mais ainda, os stalinistas, viam a democracia como uma mera forma de ditadura da burguesia, que poderia ser útil, em determinadas circunstâncias, para eles tomarem o poder. Ou seja, tinham uma visão instrumental da democracia. Com essa postura permitiram que a democracia fosse encampada pela burguesia e apresentada como uma conquista indissociável do capitalismo. Esqueceram ter sido a democracia conquistada pelos trabalhadores através de árduo processo de lutas e a despeito das resistências da burguesia. Coloca-se hoje para o marxismo superar essa herança autoritária e recuperar a bandeira da democracia. Essa questão tornou-se tão óbvia que, desde a década de 1980 e até

\footnotetext{
${ }^{15}$ BL ACKBURN, Robin. op. cit. Ver o artigo do próprio R. Blackburn e o de Diane Elson: "A cconomia de um mercado socializado", pp. 249-254.

${ }^{16}$ Idem, em particular, artigo de Norberto Bobbio "O reverso da utopia", pp. 17-21.

T'cmáticas, Campinas, 3(1):1-20, jul./dez. 1994
} 
mesmo antes, esse ponto parece ter se transformado em consenso na grande parte das correntes de tradição marxista.

O colapso do socialismo real atingiu duramente o marxismo. Mesmo aquelas correntes que há décadas teciam severas críticas à sociedade soviética viram-se mergulhadas em profunda crise. Isto porque, apesar dessas críticas, consideravam que a Revolução de 1917 foi efetivamente uma ruptura com o capitalismo. Porém, essa identificação parece não ser suficiente para explicar os estragos acarretados pelos acontecimentos no leste-europeu. Parece que, sobrepondo-se ao problema do colapso do socialismo real, as transformações do capitalismo nas últimas três décadas, só agora mais claramente visíveis, levantam uma série de problemas que também põem em questão o materialismo histórico.

\section{3 - A Reestruturação do Capitalismo}

O capitalismo, como assinalam Hobsbawm e Enzenberger, respondeu, em certo sentido, a importantes bandeiras do socialismo. Nos países ricos, graças em grande medida à social-democracia, o padrão de vida melhorou bastante e os pobres possuem certas proteções contra a miséria. Portanto, mesmo agora com a volta do desemprego estrutural e com a crise do Estado de Bem-Estar, não dá para dizer que a superação da miséria e do desemprego só seja possível com o socialismo. Além disso, devido ao avanço da social-democracia, o capitalismo, depois da Segunda Guerra, incorporou uma série de aspectos até então considerados tipicamente socialistas, como o planejamento economico e a propriedade estatal de indústrias e serviços, o que faz com que as economias capitalistas sejam, na verdade, economias mistas e não economias de mercado puro. A onda neoliberal, liderada por Reagan e Thatcher, que vigorou nos últimos 15 anos e que agora enfrenta sérios problemas, não conseguiu reverter esse quadro. ${ }^{17}$

\footnotetext{
${ }^{17}$ Idem. Ver os já citados artigos de Hobsbawm e o de H. M. Enzenberg: "Modos possiveis de caminhar: o post-scriptum da utopia", pp. 35-36.

Temáticas, Campinas, 3(4):1-20, jul./dez. 1994
} 
Entretanto a situação do capitalismo não é nada tranqüila, como se poderia imaginar, depois da derrocada do "socialismo real". O sistema capitalista passa por uma crise estrutural, que se arrasta desde meados dos anos 70. A partir da crise do petróleo, em 1973, a economia capitalista vem apresentando um desempenho sofrível, com taxas médias de crescimento bastante inferiores às do período anterior. A intensa internacionalizaçāo do capital e o padrão de acumulação flexível que vem substituindo o fordismo, ao invés de atenuarem a crise, contribuem para o seu aprofundamento, estando mesmo entre as causas de sua persistencia. ${ }^{18}$

A nova estruturação do capitalismo, ao intensificar o emprego de capital constante (robótica e informatização), ao introduzir novas formas de organizaçāo do trabalho (trabalho temporário, trabalho parcial, terceirização de produção e serviços etc.) e ao limitar a eficácia e a abrangência das políticas anticíclicas devido à globalização da economia, que tolhe a soberania dos Estados nacionais, cria sérios problemas de mercado e emprego. De um lado, as novas formas de organização do processo de trabalho e a robotização/informatização da produção e dos serviços apontam para o retorno do desemprego estrutural, como mostram os dados sobre o desemprego dos países desenvolvidos. De um outro lado, a globalização tende a tornar obsoletas as políticas econômicas nacionais, responsáveis, em boa medida, pelo ciclo expansivo do pós-guerra, pois a intensa internacionalização das finanças e da produção implicam a adoção de maneira generalizada de políticas econômicas de caráter ortodoxo, que garantam a estabilidade fiscal, monetária e cambial e o livre comércio.

O baixo desempenho das economias dos países pobres, outra característica marcante dessa nova estruturação capitalista, em nada

\footnotetext{
${ }^{18}$ Il ARVEY, David (1992). Condição pós-moderna. São Paulo, Loyola. LIPIEIZ, Alian. op. cit. e KURZ, Robert (1992). O colapso da modernização. Da derrocada do socialismo de cascrna à crise da cconomia mundial, Rio de Janeiro, Civilização Brasileira.
}

Temáticas, Campinas, 3(4):1-20, jul./de\%. 1994 
contribui para contornar esses problemas; ao contrário, agrava-os. Tudo leva a crer em um aumento assustador do número de marginalizados do consumo e do emprego em escala mundial. $\Lambda$ industrialização recente de alguns países asiáticos e de algumas outras regiōes do chamado Terceiro Mundo, apesar de questionar a concepção clássica do imperialismo e de indicar o surgimento de uma nova divisão internacional do trabalho, caracterizada pela desconcentração industrial, não altera a situação do conjunto dos países do mundo não-desenvolvido. Para os países pobres, a configuração que vem se delineando atualmente no mundo, aparentemente, deixa-os em um beco sem saída. A carência de capitais, de uma força de trabalho mais qualificada e de tecnologia moderna, inviabiliza que acompanhem o salto tecnológico em curso no mundo desenvolvido. Mais do que isso, é impossível, tudo indica, para esses países, alcançarem o padrão de desenvolvimento e consumo dos países ricos, pois, caso conseguissem, criariam uma crise ecológica de grandes proporções, a ponto de inviabilizar todo o sistema. Isso aponta para outro problema central do capitalismo: seu limite ecológico, que já aparece como problema real no nosso horizonte, mesmo com o desenvolvimento abarcando um número bastante restrito de países.

Se, por um lado, a persistência e, até mesmo, o aprofundamento das contradições do capitalismo contemporâneo reforçam a necessidade de uma teoria crítica como o marxismo, inclusive mostrando a pertinência de várias de suas hipóteses; por outro lado, levantam, como dissemos, problemas que atingem o próprio núcleo fundamental da teoria.

Um dos aspectos mais importantes dessas transformações consiste na chamada "Revolução Tecnológica", que implica em novas formas de organização do processo de trabalho e em uma redução do emprego. As conseqüências para a classe trabalhadora são abrangentes. Observa-se um aprofundamento de tendências delineadas no pós-guerra: a diminuição relativa do operariado e o crescimento das chamadas classes médias, do trabalho não manual, do trabalho par-

Temáticas, Campinas, 3(4):1-20, jul./dez. 1994 
cial e do desemprego estrutural. Essas mudanças contribuem para uma segmentação da classe trabalhadora e para uma diminuição de sua consciência e capacidade de mobilização. Nada aponta para uma classe trabalhadora revolucionária. A estratégia reformista também enfrenta problemas bastante sérios: recuo do eleitorado dos partidos reformistas, esvaziamento dos sindicatos, crise do Estado do BemEstar etc. Parece que estamos frente ao fim da classe trabalhadora, como a conhecemos hoje, ou como diz Hobsbawm: frente ao fim do movimento trabalhista clássico. ${ }^{19}$

O ponto central parece ser o declínio da consciência de classe do proletariado, a base dos movimentos trabalhistas e dos partidos socialistas e comunistas.

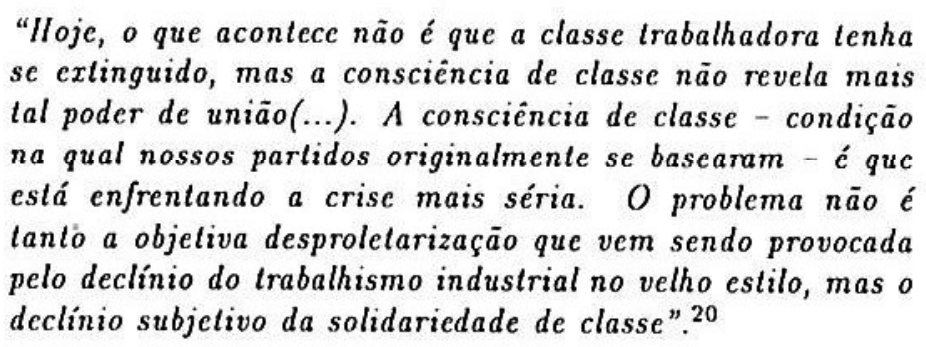

A crise de identidade e solidariedade da classe trabalhadora, decorrente de complexos processos políticos, sociais, econômicos e culturais, delineados no pós-guerra, tem como conseqüência a segmentação, desorganização e a despolitização da classe trabalhadora, dificultando sobremaneira a ação política dos trabalhadores como classe.

Essas mudanças questionam um dos pontos centrais da teoria marxista: a classe trabalhadora como sujeito revolucionário que construiria o socialismo. Marx tinha uma visão preconcebida da

\footnotetext{
${ }^{19}$ HOBSBAWM, Eric J. (1992). Estratégias para uma esquerda racional. Rio de Janeiro, Paz e Terra, pp. 179-188.

${ }^{20}$ Idem, ibidem, pp. 182 e 184.

Temáticas, Campinas, 3(4):1-20, jul./dez. 1994
} 
classe trabalhadora, que pouco tinha a ver com a classe concreta, historicamente determinada. Idealizava-a como instrinsecamente revolucionária, o que não era, mesmo na época de seu esplendor. A visão preconcebida de Marx ganhou substância quando, a partir do final do século passado, observa-se um florescimento dos partidos socialistas embasados no proletariado, cuja tendência parecia ser constituir a maioria da sociedade, e no marxismo. Essas características parecem ser específicas de um determinado período histórico. Hoje, porém, isso não parece mais se sustentar, pois, nos países que deveriam ser o centro da revolução mundial, a classe trabalhadora tendeu para a social democracia. ${ }^{21}$

Não apenas o enfraquecimento do movimento operário questiona esse ponto, mas também o surgimento de vários movimentos sociais (movimento ecológico, movimento feminista etc.), que reivindicam autonomia em relação ao movimento dos trabalhadores $\mathrm{e}$ apresentam dificuldades em ser explicados como movimentos de caráter classista. Sem falar no ressurgimento dos nacionalismos, que sempre tiveram um tratamento polêmico na teoria. O marxismo também enfrenta problemas para incorporar o crescente número de excluídos como agentes de uma transformação social. O marxismo encontra certa dificuldade em incorporar essa pluralidade de objetivos e sujeitos no sel esquema teórico.

O vigor desses movimentos contrasta com a aparente apatia e desmobilização dos trabalhadores. Além disso, os trabalhadores e os marginalizados do sistema não parecem atraídos pelo ideal socialista, antes, sim, pela sociedade de consumo e pelo ideário capitalista, que fomenta um individualismo alienante, e deprecia a igualdade como um dos valores fundamentais da vida pública. A falta de perspectiva acaba por fortalecer posições de cunho fascista e racista; vide a onda de xenofobia que varre hoje a Europa.

\footnotetext{
${ }^{21}$ Idem, op. cit.
}

Temáticas, Campinas, 3(4):1-20, jul./dez. 1994 
As esperanças do marxismo, aparentemente, desmancharam-se no ar, embora inúmeros aspectos da análise marxista do capitalismo tenham se mostrado corretos. A crescente socialização da produção, por exemplo, confirmou-se plenamente. Os avanços tecnológicos e as novas formas de organização do processo de produção, ao reduzirem sobremaneira a necessidade de força de trabalho, tornam o trabalho cada vez mais supérfluo, ao mesmo tempo que abrem enormes possibilidades de realização humana. Mas a apropriação dessa produção crescentemente socializada continua privada, restringindo esse potencial de realização a uma diminuta parcela da população do planeta e tendendo jogar países e continentes na estagnação.

No contexto atual, parece difícil aceitar que a luta de classe entre capitalistas e trabalhadores leve necessariamente ao socialismo e que este seja uma fase de transição para uma sociedade sem classes, livre e igualitária. O desmoronamento do "socialismo real", o enfraquecimento da classe trabalhadora, o esgotamento e o fracasso dos processos revolucionários no chamado 'Terceiro Mundo e o descrédito nos valores da esquerda indicam a necessidade de uma profunda revisão da tradição marxista.

"Com efeito, para o senso comum da época, todas as idéias que em dado momento formaram uma crença no socialismo são hoje outras tantas inutilidades. A produção $\mathrm{cm}$ massa foi ultrapassada pelo pós-fordismo. A classe trabalhadora é uma tênue lembrança do passado, a propriedade colctiva é uma garantia de ineficiència e tirania. A igualdade substancial é incompativel com a liberdade ou a produtividade. (...) Até que ponto esse popular veredito é conclusivo?" 22

Não temos condições de responder conclusivamente a indagação. Está em aberto ainda se o marxismo, ou os marxismos, conseguirão superar os desafios que parecem desqualificá-lo como um programa

\footnotetext{
${ }^{22}$ ANDERSON, Perry (1992). O fim da História. De Hegel a Fukuyama.
} Rio de Janeiro, Zahar, pp. 120-121.

Temáticas, Campinas, 3(4):1-20, jul./dez. 1994 
tcórico prático consistente e criativo. As dificuldades não são nada desprezíveis, pois os questionamentos atingem proposições centrais do marxismo, responsáveis, em larga medida, pela enorme influência teórica e prática dessa teoria no mundo contemporâneo: a história caminha no sentido do socialismo, não como concretização de uma fantasia utópica, mas como fruto do desenvolvimento do modo de produção capitalista, que geraria as condições materiais e subjetivas para a nova ordem, entre as quais a formação de uma classe trabaThadora revolucionária. Enfim, está em questão a própria concepção materialista da história.

No entanto, o desmoronamento do "socialismo real" não pode ser encarado, como pretendem os liberais, como a vitória definitiva do capitalismo e até mesmo como o "fim da história" na versão de Fukuyama. Sem dívida, como assinala Hobsbawm, a crise do socialismo significou, para as classes dominantes do ocidente, o fim do medo da revolução social. Medo que as acompanhou desde 1917 - que as induziu, sob a pressão de um crescente e combativo movimento operário, a implementarem ou aceitarem, um vasto programa de reformas com o intuito de melhorar as condiçōes de vida e as perspectivas dos dominados. Deste ponto de vista, as classes dominantes sentem-se mais tranquiilas e seguras de sua dominação. P’orém o capitalismo, no seu ímpeto expansivo, engendra continuamente novas contradições. O mercado, deixado por si só, gera desigualdades, injustiças e desequilíbrios. $A$ distância entre países ricos e pobres tem aumentando rapidamente nas últimas décadas e, mesmo nos países desenvolvidos, cresce de maneira assustadora o número de desempregados e marginalizados. Outro problema cada ve\% mais essencial Co de um desenvolvimento que respeite a preservação dos recursos ambientais. O capitalismo não tem mostrado condições de resolver esses problemas. Pelo contrário, parece que na nova fase do capitalismo, iniciada nesse momento, tais questōes tendem a se agravar. 1 : a partir de questões colocadas além da capacidade de o capitalismo responder que se abre a possibilidade de o socialismo e da tradição marxista renascerem das cin\%as.

Timaticas, (ampinas, 3(4):1-20, jul./de\%. 1994 